\title{
Expression of the $S$ glycoprotein of transmissible gastroenteritis virus (TGEV) in transgenic potato and its immunogenicity in mice
}

\author{
Dong-Joo Ahn ${ }^{1, \dagger}$, Jung Won Youm ${ }^{1, \dagger}$, Suk Weon Kim², Won Kee Yoon ${ }^{3}$, Hyoung Chin Kim ${ }^{3}$, Tai-Young Hur ${ }^{4}$, \\ Young Hee Joung ${ }^{5}$, Jae-Heung Jeon ${ }^{1}$, Hyun Soon Kim ${ }^{1, *}$ \\ ${ }^{1}$ Plant System Engineering Center, and ${ }^{2}$ Microbial Resource Center, KRIBB, 125 Gwahangno, Yuseong-gu, Daejeon 305-806, Korea \\ ${ }^{3}$ Laboratory Animal Resource Center, KRIBB, 685-1, Ochang 305-333, Korea \\ ${ }^{4}$ National Institute of Animal Science, RDA, Cheonan 330-801, Korea \\ ${ }^{5}$ School of Biological Sciences and Technology, Chonnam National University, Gwangju 500-757, Korea
}

(Received: April 18, 2013; Revised: October 9, 2013; Accepted: October 16, 2013)

\begin{abstract}
Transgenic plants have been tested as an alternative host for the production and delivery of experimental oral vaccines. Here, we developed transgenic potatoes that express the major antigenic sites A and D of the glycoprotein $\mathrm{S}$ from transmissible gastroenteritis coronavirus $\left(\mathrm{TGEV}_{-\mathrm{S}_{0.7}}\right)$ under three expression vector systems. The DNA integration and mRNA expression level of the TGEV-S $\mathrm{S}_{0.7}$ gene were confirmed in transgenic plants by PCR and northern blot analysis. Antigen protein expression in transgenic potato was determined by western blot analysis. Enzyme-linked immunosorbent assay results revealed that based on a dilution series of Escherichia coli-derived antigen, the transgenic line P-2 had TGEV-S ${ }_{0.7}$ protein at levels that were $0.015 \%$ of total soluble proteins. We then examined the immunogenicity of potato-derived $\mathrm{TGEV}_{-\mathrm{S}_{0.7}}$ antigen in mice. Compared with the wild-type potato treated group and synthetic antigen treated group, mice treated with the potato-derived antigen showed significantly higher levels of immunoglobulin (Ig) $\mathrm{G}$ and $\mathrm{IgA}$ responses.
\end{abstract}

Keywords : oral administration, potato-derived antigen, transmissible gastroenteritis virus, transgenic plant

\section{Introduction}

Transmissible gastroenteritis (TGE) is a highly contagious disease in pigs that is caused by the TGE virus (TEGV). This coronavirus infection is characterized by an acute watery diarrhea, dehydration, vomiting, and high mortality in seronegative suckling piglets $[1,10,11]$. TGEV contains three structural proteins designated as integral membrane protein (M), nucleocapsid $(\mathrm{N})$, and spike (S) [17]. Among the proteins, neutralizing antibodies against the virus are induced mainly to glycoprotein $\mathrm{S}$, which plays an important role in viral attachment with specific host cell receptors with subsequent penetration into the cells by membrane fusion $[9,25]$. Four major antigenic sites (A, B, C, and D) are known on the amino-terminal domain of the $S$ protein [3]. Of these wellcharacterized epitopes, $\mathrm{A}$ and to a lesser extent $\mathrm{D}$ are essential factors for inducing neutralization.

With the development of molecular biology tools, genetic engineering of vaccines has shown advantages. Available systems for traditional and commercial vaccines include bacterial, yeast, insect, and mammalian cell cultures. Although these systems are highly efficient and have specific benefits, new alternative systems that take into account cost-effectiveness and greater safety are required for the next generation of vaccines. Recently, plants have been viewed as an attractive production host for heterologous protein production, as for vaccines. The advantages of plant-based vaccines include high scalability, a low cost that allows for local production and minimal plant material processing, lack of human or animal pathogens, and ability to produce target proteins with desired biological functions [27]. Also, transgenic plants offer a suitable protein production option for oral subunit vaccines because the rigid wall of the plant cells delays digestion of antigenic proteins and enables the intact antigens to reach the gut-associated lymphoid tissue $[2,15]$. Many research groups have demonstrated the production of functional antigens in plants that are then capable of eliciting specific immune responses in the gastrointestinal tract [18], and a number of formulations are being assessed in clinical trials, as recently reviewed by Yusibov et al. [28].

The glycoprotein $\mathrm{S}$ of TGEV (TGEV-S) is a valid target for developing oral plant-derived vaccines against TGE because

\footnotetext{
*Corresponding author

Tel: +82-42-860-4493, Fax: +82-42-860-4599

E-mail: hyuns@kribb.re.kr

${ }^{\top}$ The first two authors contributed equally in this work.
} 
A

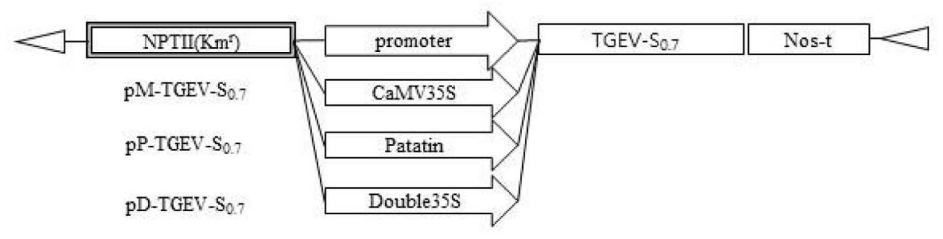

B
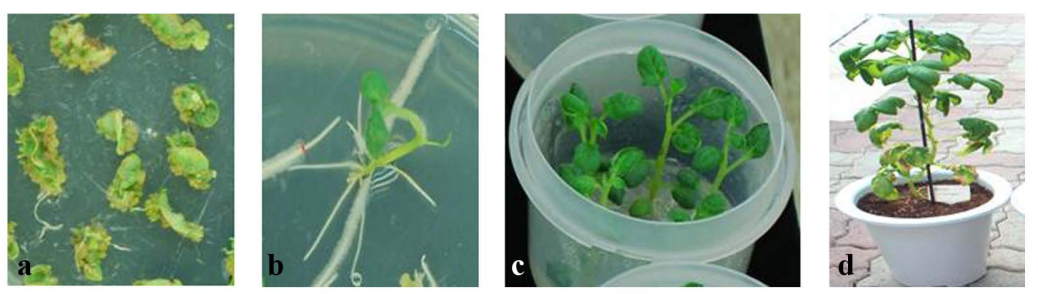

C

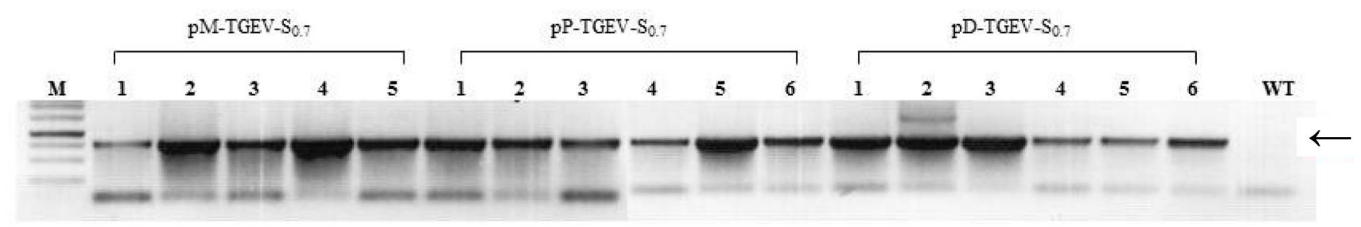

Fig. 1. (A) Structure of vector constructs pM-TGEV-S $\mathrm{S}_{0.7}$, pD-TGEV- $\mathrm{S}_{0.7}$, and pP-TGEV- $\mathrm{S}_{0.7}$. NPTII, neomycin phosphotransferase II; Nos-T, nopaline synthase terminator. (B) Transformation and production of transgenic plants using leaf segments as starting materials. (a) Regeneration of shoots from callus cultured on the selection medium containing $50 \mathrm{mg} / \mathrm{L}$ kanamycin. (b) Well-rooted transgenic plantlets on the MS basal medium. Plantlets in the plastic pots (c) for acclimation or in the soil pot (d). (C) PCR detection of TGEV- $\mathrm{S}_{0.7}$ gene in transgenic potato lines. The fragment (700 bp) of the TGEV-S $\mathrm{S}_{0.7}$ gene was amplified as shown by an arrow. Lane $\mathrm{M}$ is a 1-kb ladder. WT; genomic DNA of non-transgenic potato as a negative control.

of its immunogenicity and resistance to degradation in the gut [7]. In the present article, we used the potato plant as a host to express the glycoprotein $\mathrm{S}$ containing only antigenic sites $\mathrm{A}$ and $\mathrm{D}$ and to act as an antigenic carrier in oral vaccination of mice.

\section{Materials and Methods}

\section{Vector construction}

A 702 bp DNA fragment containing the A and D antigenic sites of the TGEV-S protein $\left(\mathrm{TGEV}^{-\mathrm{S}_{0.7}}\right)$ was amplified with $\mathrm{KpnI} / \mathrm{NcoI}$-linked sense primer (ggtacc ccatgg atg aaa aaa cta ttt gtg gtt ttg) and SacI-linked antisense primer (gagctc tta tat aac agc tgt ggc atc taa) pairs using cDNA of TGEV-S (kindly provided by Professor Chul-Joong Kim at Chungnam National University) as the template. The PCR product was cloned into the TOPO TA cloning vector (Invitrogen, USA), yielding TA-TGEV-S ${ }_{0.7}$ and verified by DNA sequencing (Genotech, Korea). The KpnI-SacI fragment from TA-TGEV-S ${ }_{0.7}$ was ligated into a pMBP1 [20] or pPAT [26] expression vector to make pM-TGEV-S $\mathrm{S}_{0.7}$ or pP-TGEV-S $\mathrm{S}_{0.7}$ (Fig. 1A). The NcoI-SacI fragment was ligated into the pD35S [8] expression vector to make pD-TGEV-S ${ }_{0.7}$ (Fig. 1A). These transformation vectors were introduced into $A$. tumefaciens strain LBA4404.

\section{Potato transformation}

Agrobacterium was cultured in YEP $(10 \mathrm{~g} / \mathrm{L}$ Bacto peptone, $10 \mathrm{~g} / \mathrm{L}$ yeast extract, $5 \mathrm{~g} / \mathrm{L} \mathrm{NaCl}$ ) medium supplemented with antibiotics. In vitro-grown leaves were immersed in the suspension of Agrobacterium for $15 \mathrm{~min}$, blotted on filter paper, and cultured on co-cultivation medium (MS salts with vitamins, $2 \mathrm{mg} / \mathrm{L} \mathrm{2,4-dichlorophenoxyacetic} \mathrm{acid,} \mathrm{pH} 5.8$ ) for 2 days at $22 \sim 25^{\circ} \mathrm{C}$ in the dark. The leaves were then transferred onto regeneration medium (MS salts with vitamins, $2 \mathrm{mg} / \mathrm{L}$ zeatin, $0.01 \mathrm{mg} / \mathrm{L}$ a-naphthaleneacetic acid, 0.1 $\mathrm{mg} / \mathrm{L}$ gibberellic acid, $100 \mathrm{mg} / \mathrm{L}$ kanamycin, $500 \mathrm{mg} / \mathrm{L}$ carbenicillin). All plant hormones and antibiotics were filtersterilized and added to the autoclaved medium. Leaves were transferred to fresh medium every 2 weeks and incubated at $22 \sim 5^{\circ} \mathrm{C}$ under a 16/8-h (light/dark) photoperiod. Regenerated shoots were transferred onto MS medium supplemented with $100 \mathrm{mg} / \mathrm{L}$ kanamycin and $500 \mathrm{mg} / \mathrm{L}$ carbenicillin. The transformants were transferred to a greenhouse, in which they were allowed to grow naturally, and were used in further analyses (Fig. 1B).

\section{Molecular characterization of transgenic plants}

DNA analysis: Genomic DNA was isolated from potato leaves using a cetyltrimethylammonium bromide-based method [4]. PCR was performed using genomic DNA (100 ng) of each plant as a template for NPTII and TGEV-S ${ }_{0.7}$ genes. The 
primers for NPTII gene amplification were F (5'-atg att gaa caa gat gga ttg cac-3') and R (5'-tca gaa gaa ctc gtc aag aag gcg-3'), and the primer pair for the TGEV-S 0.7 gene was $\mathrm{F}$ (5'-atg aaa aaa cta $\mathrm{ttt}$ gtg gtt $\mathrm{ttg}-3^{\prime}$ ') and $\mathrm{R}$ (5'-tta tat aac agc tgt ggc atc taa-3'). About $30 \mu \mathrm{g}$ of total genomic DNA was digested with $\mathrm{SacI}$ to confirm the copy number of the inserted T-DNA for each vector-derived transformant. The digested DNA was hybridized with digoxigenin (DIG)-labeled TGEV$\mathrm{S}_{0.7}$ probe, which was generated with the PCR DIG Labeling Mix (Roche Diagnostics, Germany) using the specific primer set for the TGEV-S 0.7 gene. After hybridization overnight, membrane hybridization was detected using the DIG Detection Kit following the manufacturer's instructions (Roche Diagnostics).

Northern blotting: RNA for northern blotting was extracted using the RNAgents Total RNA isolation system (Promega, USA). Thirty micrograms of total RNA was separated by electrophoresis on a $1 \%$ formaldehyde-agarose gel in $1 \times$ MOPS buffer and then blotted to a nylon membrane. The membranes were hybridized with a DIG-labeled probe at $50^{\circ} \mathrm{C}$ overnight and detected using the Dig Detection kit. Northern hybridization was carried out following the same procedure as described for Southern blot analysis, with some modification where necessary.

Western blotting: Transgenic potato plants were analyzed to detect the TGEV-S recombinant protein using an immunoblot detection method with rabbit polyclonal anti-TGEV sera (supplied by Youngin Frontier, Korea). Tubers were ground in liquid nitrogen and homogenized with extraction buffer (phosphate buffered saline [PBS], pH 7.4, 1 mM EDTA, pH8.0, $0.2 \% \beta$-mercaptoethanol) and $1 \times$ protease inhibitor (Roche), followed by centrifugation twice at $12,000 \times g$ for $15 \mathrm{~min}$ at $4^{\circ} \mathrm{C}$ to remove insoluble cell debris. The total soluble protein (TSP) was fractionated on a $12 \%$ SDS-PAGE gel and transferred to a polyvinylidene fluoride (PVDF) membrane (Millipore, USA). Detection was performed with the NBT/BCIP stock solution (Sigma-Aldrich, USA) according to the manufacturer's protocol.

Enzyme-linked immunosorbent assay (ELISA) for quantification: The expression levels of potato-expressed TGEV$\mathrm{S}_{0.7}$ protein were determined by ELISA. Briefly, microtiter plates were coated with centrifuged transgenic plant extracts (50 $\mu \mathrm{g}$ of TSP) and Escherichia (E.) coli-derived recombinant $\mathrm{TGEV}-\mathrm{S}_{0.7}$ with a serial dilution as a standard curve, incubated overnight at $4^{\circ} \mathrm{C}$. The plates were washed three times with PBST buffer $(1 \times$ PBS with $0.05 \%$ Tween-20). Consecutively, $200 \mu \mathrm{L} /$ well of $5 \%$ skim milk in PBST was added for blocking, loaded with $100 \mu \mathrm{L}$ per well of $1: 1000$ diluted rabbit polyclonal anti-TGEV sera, and incubated for 2 $\mathrm{h}$ at $37^{\circ} \mathrm{C}$, followed by washing the wells three times with PBST buffer. The plate was then incubated with $100 \mu \mathrm{L}$ per well of secondary antibody, a $1: 5,000$ dilution of horseradish peroxidase (HRP)-conjugated anti-rabbit IgG (Sigma) for $2 \mathrm{~h}$ at $37^{\circ} \mathrm{C}$. The plate was finally incubated with $100 \mu \mathrm{L}$ per well of 3,3',5,5'-tetramethylbenzidine (TMB) substrates (Pierce,
USA) for $10 \mathrm{~min}$ at room temperature. Absorbance at $\mathrm{OD}_{450 \mathrm{~nm}}$ was measured in a microplate reader (Model 680; Bio-Rad Laboratories, USA).

\section{Mouse immunization and antibody detection}

Immunization of mice: Immunogenicity of potato-derived TGEV-S ${ }_{0.7}$ protein was evaluated using 5-week-old Balb/c mice. Animal study protocol was approved by the Institutional Animal Care and Use Committee of the KRIBB (approval number: KRIBB-AEC-11089), and all experiments were conducted in accordance with the Guide for the Care and Use of Laboratory Animals. The mice were divided into three groups, with five individuals in each group. One group of mice (called group TG) was immunized with $0.5 \mathrm{~mL}$ of the transgenic potato tuber extract containing $25 \mu \mathrm{g}$ TGEV-S $\mathrm{S}_{0.7}$ antigen in PBS buffer. The negative control (designated group NC) mice received wild-type (WT) potato extract, and the other group of mice, group PC, was immunized with $25 \mu \mathrm{g}$ synthetic $\mathrm{TGEV}-\mathrm{S}_{0.7}$ antigen by oral administration. Immunization was performed using a $1 \mathrm{~mL}$ syringe fitted with a gavage needle. All of the immunized mice were also dosed with $10 \mu \mathrm{g}$ of cholera toxin (CT, Sigma-Aldrich) per mouse per gavage as adjuvant. Before administration of the potato extracts to the mice, the animals were subjected to the intragastronic administration of $0.2 \mathrm{~mL}$ of an isotonic bicarbonate solution ( $80 \%$ Hanks' balanced salt solution and $20 \%$ of $7.5 \%$ sodium bicarbonate; Gibco BRL, USA), to neutralize stomach acidity. Immunizations in mice were performed at weekly intervals for a total period of 3 weeks (on weeks 1 , 2, and 3). All of the groups received intraperitoneal (i.p.) boosters at week 6 with a $5 \mu \mathrm{g}$ E. coli-derived TGEV-S ${ }_{0.7}$ antigen.

IgG serum detection: Before the initial immunization with the transgenic potato extract and after the final immunization, blood was drawn from the orbital plexus of each mouse to obtain antiserum samples. The TGEV-specific serum IgG response was measured by endpoint titer ELISA. Briefly, the 96-well microtiter plates (Nunc-Immuno Maxisorp, Denmark) were coated with TGEV-S $\mathrm{S}_{0.7}$ antigen (200 ng/well of $0.05 \mathrm{M}$ carbonate/bicarbonate buffer, $\mathrm{pH}$ 9.6), and then incubated overnight at $4^{\circ} \mathrm{C}$. The plates were then blocked with $5 \%$ skim milk in PBST for $1 \mathrm{~h}$ at $37^{\circ} \mathrm{C}$. Subsequently, the plates were incubated with serum samples diluted to $1: 100$ with $1 \%$ skim milk in PBST buffer for $2 \mathrm{~h}$ at $37^{\circ} \mathrm{C}$. The secondary antibody, HRP-conjugated goat antirabbit IgG (Sigma-Aldrich), was diluted to $100 \mu \mathrm{L}$ per well in appropriate concentrations $(1: 5,000)$ of PBST. The plates were finally incubated with chemiluminescent substrate, TMB peroxidase substrate solution (Pierce), for $30 \mathrm{~min}$ at $37^{\circ} \mathrm{C}$. After the confirmation of sufficient color development, we added stopping solution to the samples. The plates were then assessed for absorbance at $450 \mathrm{~nm}$.

Fecal IgA: Feces samples were collected every week after the mice had ingested the potato extracts and suspended at a concentration of $1: 10(\mathrm{w} / \mathrm{v})$ in PBS containing $0.1 \%$ Tween 20 and $0.1 \mathrm{ng} / \mu \mathrm{L}$ leupeptin (Sigma-Aldrich). After $30 \mathrm{~min}$ of 
vigorous mixing at $4^{\circ} \mathrm{C}$ using a vortex mixer, these fecal suspensions were centrifuged for $10 \mathrm{~min}$ at $12,000 \times \mathrm{g}$ at $4^{\circ} \mathrm{C}$. The supernatants were used for $\operatorname{IgA}$ analysis. The 96-well microtiter plates were then coated with anti-mouse IgA (1 $\mu \mathrm{g} / \mathrm{mL}$, Capture Antibodies; R\&D Abs, USA) in PBS (100 $\mu \mathrm{L}$ per well) and incubated overnight at $4^{\circ} \mathrm{C}$. The plates were blocked with $5 \%$ skim milk in PBST for $2 \mathrm{~h}$ at room temperature and washed three times in PBST. The extracted feces were diluted to $100 \mu \mathrm{L}$ per well in appropriate concentrations $(1: 100)$ of PBS. The plates were incubated for $2 \mathrm{~h}$ and washed three times in PBST. The secondary antibody, HRPconjugated goat anti-rabbit IgA ( $\alpha$-chain specific; R\&D Abs) was diluted to $100 \mu \mathrm{L}$ per well in appropriate concentrations $(1: 5,000)$ of PBST. The plates were then assessed for absorbance at $450 \mathrm{~nm}$.

All analyses for statistically significant differences were performed with the Kruskal-Wallis test, with $p$ values of $<$ 0.05 considered significant.

\section{Phenotype and tuber composition analysis}

Rooted plants about $5 \mathrm{~cm}$ in height were removed from the medium, and their roots were cleaned of agar residues. They were then transferred to plastic pots $(15 \mathrm{~cm}$ in diameter), 5 plants from each line were grown in a greenhouse maintained at $25^{\circ} \mathrm{C}$ under natural daylight. Twelve weeks after completion of growth, plant height, the number of tubers, and tuber weight were recorded. For compositional analysis of P2 line and WT control potato tubers, whole tuber samples were freeze-dried in liquid nitrogen and stored at $-80^{\circ} \mathrm{C}$ before analysis. Analysis of phenolic, flavonoids, and carotenoids contents were carried out as described method in Payyavula et al. [14]. Starch content in potato tubers was measured using a Megazyme Total Starch Assay kit (Biovision, USA) and supplied manufacture's protocols.

The differences between the $\mathrm{NC}$ and treatment samples were analyzed using the pair-wise $t$ test installed in the Microsoft Office Excel program. Statistical significance was assumed when $p<0.05$.

\section{Results}

\section{Generation of transgenic plants and analysis of antigen expression}

Over 50 independent in vitro shoots were obtained per each binary construct of $\mathrm{pM}-\mathrm{TGEV}-\mathrm{S}_{0.7}, \mathrm{pD}-\mathrm{TGEV}-\mathrm{S}_{0.7}$, and pP-TGEV-S $\mathrm{S}_{0.7}$ following Agrobacterium-mediated transformation on selection medium containing kanamycin. PCR analysis was performed to confirm the presence of the TGEV gene in the genomic DNA of those regenerated shoots for initial screening. PCR analysis of the TGEV gene identified the expected $700 \mathrm{bp}$ product in five $\mathrm{pM}-\mathrm{TGEV}-\mathrm{S}_{0.7}$, six $\mathrm{pP}-$ TGEV-S $_{0.7}$, and six pD-TGEV-S ${ }_{0.7}$ independent lines, respectively, whereas no products were detected from WT control plants (Fig. 1C). Only one transgenic potato per construct was confirmed as having one T-DNA insertion copy by
A

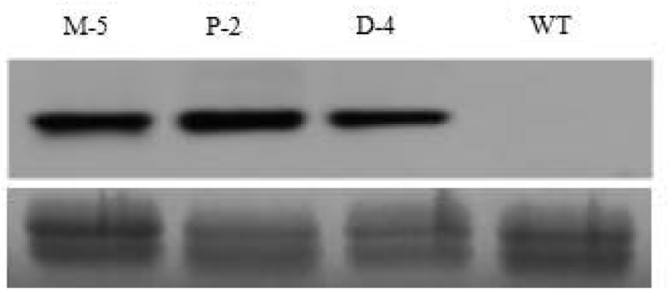

B

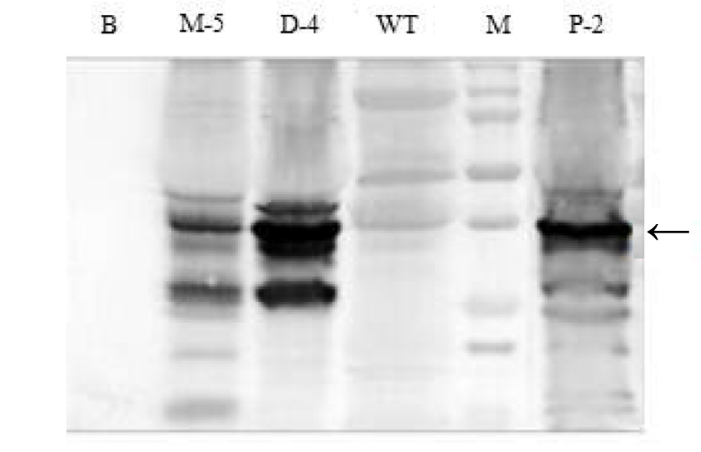

C

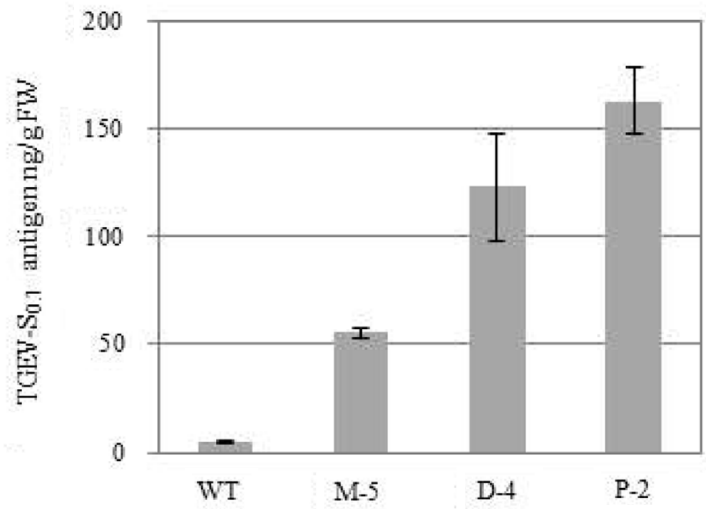

Fig. 2. (A) Northern blot analysis of transgenic potato plants, $\mathrm{M}\left(\mathrm{pM}-\mathrm{TGEV}-\mathrm{S}_{0.7}\right)-5$, D (pD-TGEV-S $\left.\mathrm{S}_{0.7}\right)-4$, and P (pP-TGEV$\mathrm{S}_{0.7}$ )-2, selected by PCR analysis with a DIG-labeled TGEV$\mathrm{S}_{0.7}$ probe. Total RNA loaded on the gel was confirmed by gel staining of rRNA (lower panel). (B) Immunoblot detection of TGEV- $\mathrm{S}_{0.7}$ protein in transgenic potato plants, M-5, D-4, and P-2. Total soluble protein (TSP, $50 \mu \mathrm{g}$ ) extracted from transgenic plants was transferred to a PVDF membrane and detected with TGEV-specific anti-rabbit polyclonal antiserum. (C) Determination of TGEV- $\mathrm{S}_{0.7}$ protein expression levels in transgenic potato tuber using ELISA analysis. Known amounts of purified TGEV-S $\mathrm{S}_{0.7}$ protein derived from E. coli were used to generate a standard control. Extracts from a non-transformed plant were used as negative control. Absorbance was measured at $405 \mathrm{~nm}$, and expression amounts were calculated from the TSP used in three replicates of the assay. Values are the mean $\pm \mathrm{SD}$ of three plants per group. B; only buffer control, M; molecular weight marker, WT; extracts from a non-transgenic control plant. 
A

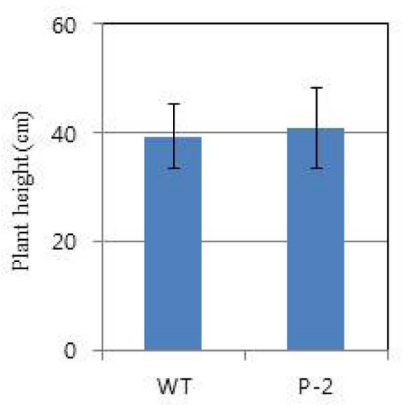

B

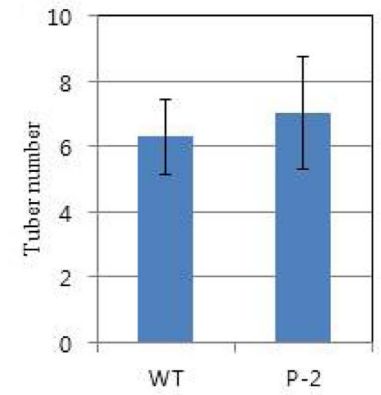

C

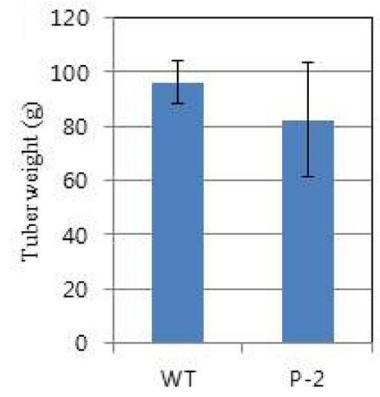

Fig. 3. Comparison analysis of plant height $(\mathrm{A}, p$ value $=0.78)$, tuber number $(\mathrm{B}, p$ value $=0.18)$, and tuber weight $(\mathrm{C}, p$ value $=0.25)$ between non-transgenic potato (WT) contol and transgenic pP-TGEV-S . $_{7}-2(\mathrm{P}-2)$ lines under normal growth conditions. Values were measured after harvesting. Data are given as mean \pm SD from five plants per group. Pair-wise $t$ test was used to compare different groups of data $(p<0.05)$.

Table 1. Comarison of tuber components between wild-type control and TGEV-expressing transgenic potato plant, P-2

\begin{tabular}{lccc}
\hline \hline & P-2 transgenic line & WT control potato & $p$ value \\
\hline Carotenoids $(\mathrm{mg} / \mathrm{g} \mathrm{dw})$ & $0.157 \pm 0.002^{*}$ & $0.098 \pm 0.005^{*}$ & 0.0008 \\
Flavonoids $(\mu \mathrm{g}$ catechin equivalent $/ 100 \mathrm{mg} \mathrm{dw})$ & $596.99 \pm 0.15$ & $63.44 \pm 0.06$ & 0.174 \\
Phenolics $(\mu \mathrm{g}$ cloroginic acid equivalent $/ 100 \mathrm{mg} \mathrm{dw}$ & $807.79 \pm 10.3$ & $761.34 \pm 4.47$ & 0.650 \\
Starch $(\% \mathrm{w} / \mathrm{w} \mathrm{dw})$ & $52.6 \pm 2.1$ & $58.4 \pm 3.2$ & 0.186 \\
\hline
\end{tabular}

Each value represents mean \pm SD from five plants per group. * Means within a row with no common superscripts differ significantly $(p<$ 0.05). WT: wild-type, non-transgenic potato as a negative control, dw: dry weight.

Southern blot analysis (data not included): $\mathrm{pM}-\mathrm{TGEV}-\mathrm{S}_{0.7}-5$, pD-TGEV-S $\mathrm{S}_{0.7}-4$, and $\mathrm{pP}-\mathrm{TGEV}-\mathrm{S}_{0.7}-2$, designated as M-5, D4 , and $\mathrm{P}-2$, respectively. These representative transformed potatoes were transferred to greenhouse conditions for phenotype analysis and detailed molecular characterization.

To determine TGEV transcript levels, total RNA from WT and transgenic potato tubers was assayed by northern blotting. Three of the transgenic lines, M-5, D-4, and P-2, which were selected based on the results of Southern blot analysis, expressed the TGEV transcript stably and at similar levels (Fig. 2A).

Immunoblot analysis was performed to detect the expression of TGEV-S $\mathrm{S}_{0.7}$ protein in the transgenic plant lines $\mathrm{M}-5$, P-2, and D-4. Signal in P-2 and D-4 was stronger than in M4 , suggesting that TGEV $\mathrm{S}_{0.7}$ protein was capable of expression in transgenic potato plants (Fig. 2B). Expression level varied depending on the insertional effect or translational processing. No TGEV-S ${ }_{0.7}$ protein was detected from WT control plants.

An ELISA assay was performed to obtain quantitative estimates of TGEV-S $\mathrm{S}_{0.7}$ protein levels in the potato plants of the three independent lines. The amounts were quantified by comparison with known amounts of purified TGEV antigen from E. coli. Based on the results of the ELISA, potato tuber tissue contained $55 \mathrm{ng}, 123 \mathrm{ng}$, and $163 \mathrm{ng}$ of TGEV-S ${ }_{0.7}$ protein per gram of fresh weight of M-5, D-4, and P-2, respectively (Fig. 2C).

Investigation of the agronomic traits of transgenic lines was conducted in the greenhouse. Plant height, number of tubers per plant, and mean weight per tuber were measured. Plant height $(p>0.05)$, tubers $(p>0.05)$, and tuber weight $(p>0.05)$ of the transgenic lines were similar to those of the WT control under normal conditions (Fig. 3). Also, there were no phenotypic abnormalities in either type of potato (data not shown). Moreover, we carried out metabolic evaluation of the P-2 potato and WT control potato by composition analysis, such as secondary metabolite or starch. Based on the analysis, the metabolite profiles between P-2 and control potatoes did not differ significantly (Table 1). These results indicate that overexpression of TGEV-S $\mathrm{S}_{0.7}$ have no adverse effect on potato growth and development, and affects neither the quantity nor the quality of metabolites $(p>0.05)$ relative to WT potatoes. Only carotenoid contents in the P-2 transgenic line were a little higher than in the WT control plant $(p<0.05)$.

\section{Antibody response of mice to the transgenic potatoes}

To assess the immunogenicity of the potato-derived TGEV-S ${ }_{0.7}$ antigen protein, Balb/c mice were immunized orally with soluble protein extracted from freeze-dried potato tubers of transgenic P-2 or WT plants. Significant responses against TGEV were detected in serum from mice fed with potato-derived TGEV-S $\mathrm{T}_{0.7}$ antigen (Fig. 4A). The response was clearly increased at 7 weeks after i.p. booster with $5 \mu \mathrm{g}$ E. coli-derived TGEV-S $\mathrm{S}_{0.7}$. Doses of $25 \mu \mathrm{g}$ of TGEV-S $\mathrm{T}_{0.7}$ antigen expressed in potato tubers were sufficient to elicit a 
A

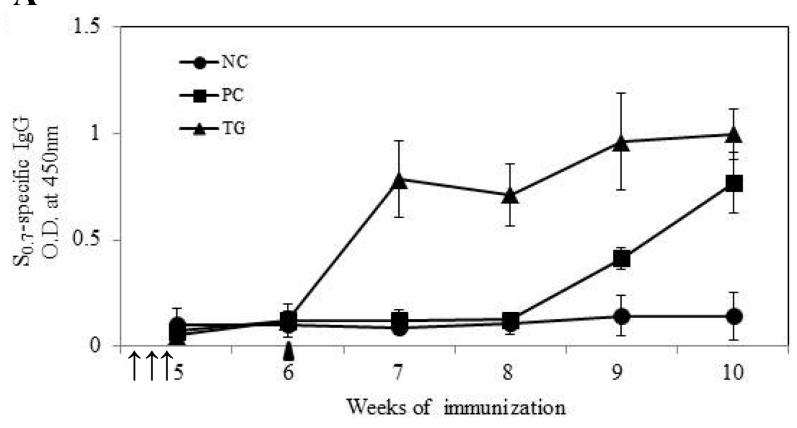

B

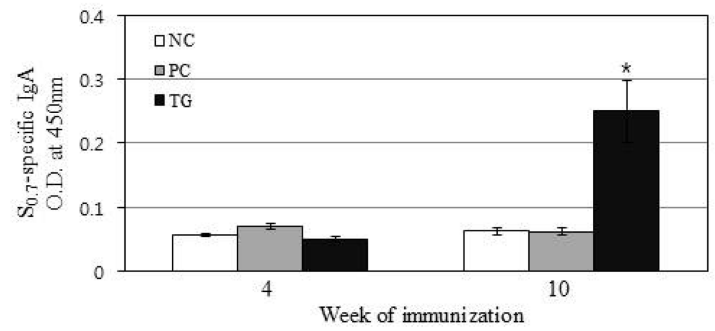

Fig. 4. Serum IgG anti-TGEV antibodies (A) and fecal IgA anti-TGEV antibodies (B) detected in mice. Mice were orally administered potato-derived TGEV-S $\mathrm{S}_{0.7}$ antigen, wild-type control potato, or synthetic TGEV antigen. All of the immunized mice were dosed with $10 \mu \mathrm{g}$ of cholera toxin as adjuvant. The antigens were administered three times, at weeks 1,2 , and $3(\uparrow)$. The black, bold arrowhead marks the boost time at week 6 with a $5 \mu \mathrm{g}$ Escherichia coli-derived TGEV-S $\mathrm{S}_{0.7}$ antigen (A). Each bar represents an average of five samples \pm SD. Statistically significant differences $(p<0.01)$ in antibody responses between groups are indicated as follows: asterisks compared with wildtype control potato and synthetic TGEV antigen. NC; wild-type control potato, PC; synthetic TGEV antigen, TG; potato-derived TGEV-S $\mathrm{S}_{0.7}$ antigen.

strong Ig response in serum, identifying this system as an effective oral delivery vehicle for TGEV antigen. Of interest, mice fed with transgenic potato expressing TGEV (the TG group) showed stronger immunogenic responses than mice administered the synthetic TGEV antigen (PC group). No immune responses were detected in mice immunized with WT control potato tubers (NC group), even after repeated or booster inoculations.

As a guide to mucosal immunogenicity, anti-TGEV-specific IgA levels were determined in fecal material from three groups of mice. As shown in Fig. 4B, small but significant production of fecal IgA was detected only in mice fed with $25 \mu \mathrm{g}$ of potato-derived TGEV-S $\mathrm{S}_{0.7}$ antigen protein after i.p. booster immunization $(p<0.01)$. This result suggests that mucosal antibody responses were induced by the potatoderived TGEV-S $\mathrm{S}_{0.7}$ antigen protein. As expected, no antigenspecific antibodies were detected in mice immunized with potato-derived proteins from WT control potato tubers. Of interest, there was no IgA antibody detection in mice fed synthetic TGEV antigen as positive control. These findings demonstrated that TGEV antigen derived from the potato plant induces a much greater anti-TGEV-specific mucosal IgA response than pure TGEV antigen.

During immunization with potato-derived TGEV antigen, none of the mice died, and weight gain was the same as those inoculated with WT control potato extracts.

\section{Discussion}

Stably integrated nuclear transgenes in potato typically yield relatively low concentrations of the recombinant protein with reported expression levels, for example, of approximately $0.01 \%$ TSP [27]. Therefore, increasing the expression level of the target protein in the plant cell is considered urgent and necessary. Generally, several factors which include transcription, translation, post-translational modification or storage of recombinant protein in the cell are involved in increasing expression level of transgene [16]. In this work, we produced TGEV-S $\mathrm{S}_{0.7}$ protein at a level of $0.015 \%$ TSP in transgenic potato tuber plants. The use of different promoters - single $35 \mathrm{~S}$, double $35 \mathrm{~S}$, and patatin promoters - was expected to improve expression levels of TGEV-S $\mathrm{S}_{0.7}$ in these plants. Although genomic PCR analysis showed bands for TGEV genes in all of the transgenic plants, three representative transgenic plants (M-5, D-4, and P-2 lines) showed highquantity mRNA bands of TGEV whereas the rest showed low expression in northern blot analysis. Because of the different and random incorporation sites of insertion of the transferred DNA into the nuclear DNA, different levels of foreign gene expression in individual transformants are expected [6]. The transgenic potato line P-2, driven by the patatin promoter, showed a similar transcript level to the others but had the highest protein expression level (163 ng/g FW) as compared to transgenic lines containing either the single $35 \mathrm{~S}$ (M-5, $55.3 \mathrm{ng} / \mathrm{g} \mathrm{FW}$ ) or double $35 \mathrm{~S}$ promoter (D$4,123 \mathrm{ng} / \mathrm{g} \mathrm{FW}$ ). Patatins are considered to be a major storage protein in potato tubers, and this protein might be manifesting the enhanced translation efficiency of the TGEV gene in the potato tuber, in agreement with a study conducted by Joung et al. [8].

Plants have emerged as attractive expression systems for the production of a broad range of heterologous molecules, such as pharmaceuticals, because they produce antigens without the danger of contamination by animal pathogens [7, 13]. Furthermore, plant-based oral vaccines offer the prospect of triggering the mucosal immune response for the prevention of infections and enable the intact antigens to reach the intestinal tissues [24]. In the late 1990s, a few efforts were made to introduce glycoprotein S of TGEV into Arabidopsis [6], potato [7], tobacco [24], and maize [19]. Gómez et al. [7] demonstrated that glycoprotein $\mathrm{S}$ of TGEV is a valid target for developing oral plant-derived vaccines against TGE because of its immunogenicity and resistance to degradation in the gut. They introduced full-length 4344 bp or N- 
terminus $2250 \mathrm{bp}$ of TGEV glycoprotein $\mathrm{S}$ into potato, resulting in $0.02 \mu \mathrm{g}$ of purified TGEV per $30 \sim 60 \mu \mathrm{g}$ soluble protein of leaf sample. Four major antigenic sites have been described in glycoprotein S, among which site A is immunodominant. Recombinant protein lacking the A antigenic site, or with a deletion including the putative receptor-binding sites and the D antigenic site, cannot induce levels of neutralizing antibodies similar to what the whole S protein induces [23].

In this study, we sought to develop the transgenic potato expressing 700 bp containing only epitope A plus the D antigenic sites. The potato-derived recombinant TGEV- $\mathrm{S}_{0.7}$ protein was tested for its immunogenicity in mice. Specific IgG antibodies were detected in the sera of orally immunized mice, and IgA antibodies were detected in the fecal samples of these animals, indicating that the plant-derived TGEV-S $\mathrm{S}_{0.7}$ protein could induce both systemic and mucosal immunity. Mucosal IgA plays a critical role in the early stages of host defense against many invading pathogens [5]. Therefore, designing vaccines that can generate secretory IgA antibodies is important. Similar results have been reported of a high level of anti-TGEV-S $\mathrm{N}_{\mathrm{N}}$ IgA observed in intestinal lavages of mice immunized with $\mathrm{L}_{\mathrm{NZ}} 9000-\mathrm{rTGEV}-\mathrm{S}_{\mathrm{N}}$ [21]. Previous findings $[12,22]$ also suggest that animals would benefit from vaccines provoking immune responses in intestinal mucosa.

Although mice fed with the potato-derived TGEV-S $\mathrm{S}_{0.7}$ showed lower than expected amounts of induced antibodies, a detectable TGEV-specific IgG or IgA response was sufficiently elicited from the immune system in this murine model. Based on these experiments, we are in the process of confirming the immune protection of the potato expressing TGEV-S $\mathrm{S}_{0.7}$ antigen protein in pigs. The harmless nature of the potato tuber would make it an ideal candidate for delivering heterologous antigens in an oral vaccine.

Identity between the transformed potato plant and WT control plants is considered important for developing a commercial product. Here we evaluated phenotypic characteristics, agronomic performance, and compositional analysis of the P2 transgenic line and the WT control potato. Overall, the differences in evaluation value are within the error range. We conclude that transgenic potato expressing the TGEV antigen could be viable for use in developing oral vaccines.

\section{Acknowledgments}

This study was supported by the Korea Research Institute of Bioscience \& Biotechnology (KRIBB) Research Initiative program and IPET research program of Ministry of Agriculture, Food and Rural Affairs, Republic of Korea. The authors thank Prof. Chul-Joong Kim at Chungnam National University for providing us with the plasmid DNA containing TGEV glycoprotein $\mathrm{S}$ and comments.

\section{References}

1. Abid NBS, Chupin SA, Bjadovskaya OP, Andreeva OG,
Aouni M, Buesa J, Baybikov TZ, Prokhvatilova LB. Molecular study of porcine transmissible gastroenteritis virus after serial animal passages revealed point mutations in S protein. Virus Genes 2011, 42, 212-219.

2. Chia MY, Hsiao SH, Chan HT, Do YY, Huang PL, Chang HW, Tsai YC, Lin CM, Pang VF, Jeng CR. Immunogenicity of recombinant GP5 protein of porcine reproductive and respiratory syndrome virus expressed in tobacco plant. Vet Immunol Immunopathol 2010, 135, 234242.

3. Delmas B, Rasschaert D, Godet M, Gelfi J, Laude $\mathbf{H}$. Four major antigenic sites of the coronavirus transmissible gastroenteritis virus are located on the amino-terminal half of spike glycoprotein S. J Gen Virol 1990, 71, 1313-1323.

4. Doyle JJ, Doyle JL. A rapid DNA isolation procedure for small quantities of fresh leaf tissue. Phytochem Bull 1987, 19, $11-15$.

5. van Egmond $M$, van Garderen $E$, van Spriel $A B$, Damen CA, van Amersfoort ES, van Zandbergen G, van Hattum J, Kuiper J, van de Winkel JGJ. FcáRIpositive liver Kupffer cells: reappraisal of the function of immunoglobulin A in immunity. Nat Med 2000, 6, 680685.

6. Gómez N, Carrillo C, Salinas J, Parra F, Borca MV, Escribano JM. Expression of immunogenic glycoprotein $\mathrm{S}$ polypeptides from transmissible gastroenteritis coronavirus in transgenic plants. Virology 1998, 249, 352-358.

7. Gómez N, Wigdorovitz A, Castañón S, Gil F, Ordás R, Borca MV, Escribano JM. Oral immunogenicity of the plant derived spike protein from swine-transmissible gastroenteritis coronavirus. Arch Virol 2000, 145, 1725-1732.

8. Joung YH, Youm JW, Jeon JH, Lee BC, Ryu CJ, Hong HJ, Kim HC, Joung H, Kim HS. Expression of the hepatitis B surface $\mathrm{S}$ and preS2 antigens in tubers of Solanum tuberosum. Plant Cell Rep 2004, 22, 925-930.

9. Kang TJ, Seo JE, Kim DH, Kim TG, Jang YS, Yang MS. Cloning and sequence analysis of the Korean strain of spike gene of porcine epidemic diarrhea virus and expression of its neutralizing epitope in plants. Protein Expr Purif 2005, 41, 378-383.

10. Lamphear BJ, Jilka JM, Kesl L, Welter M, Howard JA, Streatfield SJ. A corn-based delivery system for animal vaccines: an oral transmissible gastroenteritis virus vaccine boosts lactogenic immunity in swine. Vaccine 2004, 22, 2420-2424.

11. Laude H, van Reeth K, Pensaert M. Porcine respiratory coronavirus: molecular features and virus-host interactions. Vet Res 1993, 24, 125-150.

12. van der Linden IFA, van der Linde-Bril EM, Voermans JJM, van Rijn PA, Pol JMA, Martin R, Steverink PJGM. Oral transmission of porcine reproductive and respiratory syndrome virus by muscle of experimentally infected pigs. Vet Microbiol 2003, 97, 45-54.

13. Monger W, Alamillo JM, Sola I, Perrin Y, Bestagno M, Burrone OR, Sabella P, Plana-Duran J, Enjuanes L, Garcia JA, Lomonossoff GP. An antibody derivative expressed from viral vectors passively immunizes pigs against transmissible gastroenteritis virus infection when supplied orally in crude plant extracts. Plant Biotechnol J 2006, 4, 623-631. 
14. Payyavula RS, Navarre DA, Kuhl JC, Pantoja A, Pillai SS. Differential effects of environmental on potato phenylpropanoid and carotenoid expression. BMC Plant Biol 2012, 12, 39.

15. Rigano MM, Dreitz S, Kipnis AP, Izzo AA, Walmsley AM. Oral immunogenicity of a plant-made, subunit, tuberculosis vaccine. Vaccine 2006, 24, 691-695.

16. Sharma AK, Sharma MK. Plants as bioreactors: Recent developments and emerging opportunities. Biotechnol Adv 2009, 27, 811-832.

17. Spaan W, Cavanagh D, Horzinek MC. Coronaviruses: structure and genome expression. J Gen Virol 1988, 69, 2939-2952.

18. Streatfield SJ, Howard JA. Plant production systems for vaccines. Expert Rev Vaccines 2003, 2, 763-775.

19. Streatfield SJ, Jilka JM, Hood EE, Turner DD, Bailey MR, Mayor JM, Woodard SL, Beifuss KK, Horn ME, Delaney DE, Tizard IR, Howard JA. Plant-based vaccines: unique advantages. Vaccine 2001, 19, 2742-2748.

20. Suh MC, Choi D, Liu JR. Cadmium resistance in transgenic tobacco plants expressing the Nicotiana glutinosa L. metallothionein-like gene. Mol Cells 1988, 8, 678-684.

21. Tang L, Li Y. Oral immunization of mice with recombinant Lactococcus lactis expressing porcine transmissible gastroenteritis virus spike glycoprotein. Virus Genes 2009, 39, 238-245.

22. Tang L, Ou D, Ge J, Xu Y, Li Y, Shi D, Xia C, Yu Y. Construction of recombinant Lactococcus lactis expressing porcine transmissible gastroenteritis spike glycoprotein and analysis of immunogenicity. Wei Sheng Wu Xue Bao 2007, 47, 340-344.

23. Tuboly T, Nagy E, Dennis JR, Derbyshire JB. Immunogenicity of the $\mathrm{S}$ protein transmissible gastroenteritis virus expressed in baculovirus. Arch Virol 1994, 137, 5567.

24. Tuboly T, Yu W, Bailey A, Degrandis S, Du S, Erickson L, Nagy É. Immunogenicity of porcine transmissible gastroenteritis virus spike protein expressed in plants. Vaccine 2000, 18, 2023-2028.

25. Wang C, Ren X. Preparation and characterization of polyclonal antibody against severe acute respiratory syndromeassociated coronavirus spike protein. Hybridoma 2010, 29, 511-516.

26. Youm JW, Kim MS, Lee BC, Kang WJ, Jeon JH, Joung HU, Kim HS. District spatio-temporal expression patterns of patatin promoter-GUS gene fusion in transgenic potato microtubers. Korean J Plant Biotechnol 2003, 30, 13-18.

27. Yu J, Langridge W. Expression of rotavirus capsid protein VP6 in transgenic potato and its oral immunogenicity in mice. Transgenic Res 2003, 12, 163-169.

28. Yusibov V, Streatfield SJ, Kushnir N. Clinical development of plant-produced recombinant pharmaceuticals. Hum Vaccines 2011, 7, 313-321. 